\title{
ASSESSMENT OF RGB AND HYPERSPECTRAL UAV REMOTE SENSING FOR GRASS QUANTITY AND QUALITY ESTIMATION
}

\author{
Raquel Alves de Oliveira ${ }^{1}$, Roope Näsi ${ }^{1}$, Oiva Niemeläinen ${ }^{2}$, Laura Nyholm ${ }^{3}$, Katja Alhonoja ${ }^{4}$, Jere Kaivosoja ${ }^{2}$, Niko Viljanen ${ }^{1}$, \\ Teemu Hakala ${ }^{1}$, Somayeh Nezami ${ }^{1}$, Lauri Markelin ${ }^{1}$, Lauri Jauhiainen ${ }^{2}$, Eija Honkavaara ${ }^{1, *}$ \\ ${ }^{1}$ Department of Remote Sensing and Photogrammetry, Finnish Geospatial Research Institute FGI, Finland - (raquel.alvesdeoliveira, \\ roope.nasi, niko.viljanen, teemu.hakala, somayeh.nezami, lauri.markelin, eija.honkavaara)@nls.fi \\ ${ }^{2}$ Natural Resources Institute Finland - LUKE, Latokartanonkaari 9, FI-00790 Helsinki, Finland - (jere.kaivosoja, oiva.niemelainen, \\ lauri.jauhiainen)@luke.fi \\ ${ }^{3}$ Valio Oy, PL 10, FI-00039 Valio, Finland - (laura.nyholm)@valio.fi \\ ${ }^{4}$ Yara Suomi Oy, Bertel Jungin aukio 9, FI-02600 Espoo, Finland - (katja.alhonoja)@ yara.com
}

Commission I, WG I/9

KEY WORDS: Hyperspectral, UAV, photogrammetry, precision agriculture, grass sward, biomass, machine learning

\begin{abstract}
:
The information on the grass quantity and quality is needed for several times in a growing season for making optimal decisions about the harvesting time and the fertiliser rate, especially in northern countries, where grass swards quality declines and yield increases rapidly in the primary growth. We studied the potential of UAV-based photogrammetry and spectral imaging in grass quality and quantity estimation. To study this, a trial site with large variation in the quantity and quality parameters was established by using different nitrogen fertilizer application rates and harvesting dates. UAV-based remote sensing datasets were captured four times during the primary growth season in June 2017 and agricultural reference measurements including dry biomass and quality parameters, such as the digestibility (D-value) were collected simultaneously. The datasets were captured using a flying height of 50 $\mathrm{m}$ which provided a GSD of $0.7 \mathrm{~cm}$ for the photogrammetric imagery and $5 \mathrm{~cm}$ for the hyperspectral imagery. A rigorous photogrammetric workflow was carried out for all data sets aiming to determine the image exterior orientation parameters, camera interior orientation parameters, 3D point clouds and orthomosaics. The quantitative radiometric calibration included sensor corrections, atmospheric correction, and correction for the radiometric non-uniformities caused by illumination variations, BRDF correction and the absolute reflectance transformation. Random forest (RF) and multilinear regression (MLR) estimators were trained using spectral bands, vegetation indices and 3D features, extracted from the remote sensing datasets, and insitu reference measurements. From the FPI hyperspectral data, the 35 spectral bands and 11 spectral indices were used. The 3D features were extracted from the canopy height model (CHM) generated using RGB data. The most accurate results were obtained in the second measurement day (15th June) which was near to the optimal harvesting time and generally RF outperformed MLR slightly. When assessed with the leave-one-out-estimation, the best root mean squared error (RMSE\%) were 8.9\% for the dry biomass using 3D features. The best D-value estimation using RF algorithm (RMSE\% $=0.87 \%$ ) was obtained using spectral features. Using the estimators, we then calculated grass quality and quantity maps covering the entire test site to compare different techniques and to evaluate the variability in the field. The results showed that the low-cost drone remote sensing gave excellent precision both for biomass and quality parameter estimation if accurately calibrated, offering an excellent tool for efficient and accurate management of silage grass production.
\end{abstract}

\section{INTRODUCTION}

Remote sensing using unmanned aerial vehicles (UAV) offers totally new prospects for applying precision agriculture (PA) techniques (Aasen et al. 2018). In the silage production, the fundamental PA tasks include the management of fertilization as well as the correct timing for harvesting in order to optimize the adequate yields with a desired quality for animal feeding under the prevailing weather, soil, and environmental conditions. In the northern countries, silage grass swards are harvested two to four times a season, and fertiliser is applied similarly once for each harvest, when aiming to achieve maximum yields. The feed quality (digestibility) in grass swards declines rapidly in the primary growth period while the yield is increasing, and knowledge of the nitrogen uptake is necessary to determine the fertilizer need for the regrowth. Thus, information on the grass quantity and quality is needed for several times in a growing season for making optimal decisions about the harvesting time and the fertiliser rate.
Fast development of lightweight multi- and hyperspectral sensor technology enable flexible UAV-based collection of spectral data, which can be used to estimate quantity and quality information on plants (eg. Geipel et al., 2016; Näsi et al., 2018a). In addition to spectra information, 3D structure of plants can be collected at the same time since frame-based sensors and modern photogrammetry enable the generation of spectral digital surface models (DSM) (Aasen et al., 2015; Oliveira et al., 2019). Especially in biomass estimation, the use of drone-based photogrammetric canopy height models (CHMs) has already showed good results (Rueda-Ayala et al., 2019; Bareth and Schellberg, 2018; Bendig et al., 2015; Li et al., 2016).

The objective of this study was to investigate and compare the efficient and low-cost UAV machine learning techniques, based on spectral and 3D data, for managing and monitoring silage grass swards. 


\section{MATERIALS AND METHODS}

\subsection{Test area}

Trial sites were established in Jokioinen, located in southwest Finland, in the summer of 2017 and introduced by Viljanen et al. (2018) and Näsi et al. (2018b). The experimental sites were established on a second-year silage production field aiming to generate large variation in the study sward. The six fertilizer rate treatment had four replicates leading to 24 main plots (plot size $12 \mathrm{~m} \times 3 \mathrm{~m}$ ), and the harvesting time was in the sub-plot. The campaign was repeated 4 times (on the $6^{\text {th }}, 15^{\text {th }}, 19^{\text {th }}$, and $28^{\text {th }}$ of June), thus, the experiment had a total of 96 plots. Samples were taken from each harvested plot for quantity and quality analyses. The dry matter yield (DMY) represented the quantity parameter and it was measured by the Haldrup forage plot harvester (Viljanen et al. 2018). Digestibility of organic matter in dry matter (D-value) was selected as the quality parameter. D-value is directly related with metabolised energy (ME) as Dvalue $(\mathrm{g} / \mathrm{kg} \mathrm{DM})$ multiplied by 0.016 provided $\mathrm{ME}$ as $\mathrm{MJ} / \mathrm{kg}$ DM and it was measured by the Valio Ltd feed laboratory, using a Near Infrared Spectroscopy (NIRS) technique (Aastveit and Marum 1989) with Foss NIR XDS equipment. The relation between biomass (DMY) and digestibility (D-value) can be seen in Fig. 1, which shows that they are negatively correlated (correlation coefficient $=-0.85$ ). As the quantity increases, the quality measured as D-value decreases.

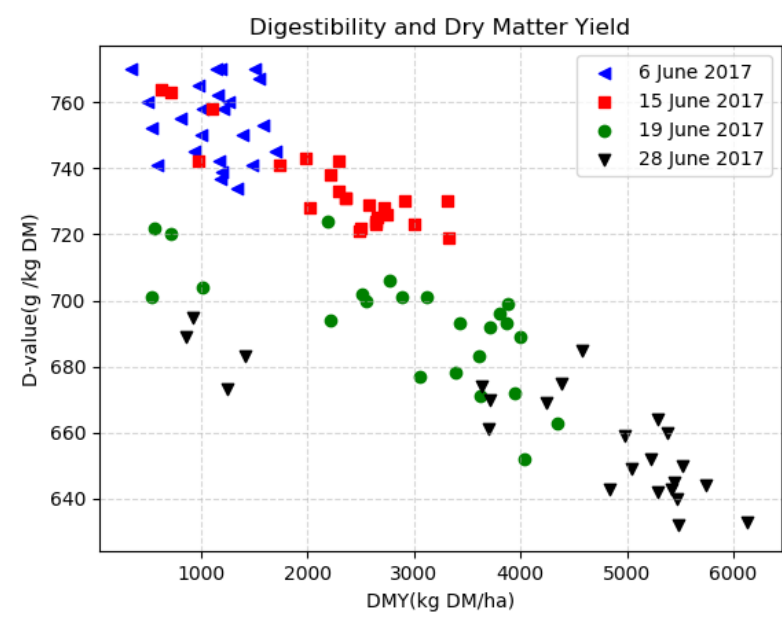

Figure 1: Reference measurements of dry matter yield (DMY) and D-value (digestible organic matter in dry matter) for each date.

\subsection{UAV campaign}

Multitemporal UAV datasets were captured four times in the trial site during the primary growth season. A quadcopter drone was equipped with a multisensory remote sensing system consisting of an RBG camera, a hyperspectral 2D frame camera, an NV08C-CSM L1 single frequency Global Navigation Satellite System (GNSS) receiver, and a Raspberry Pi singleboard computer. The RGB camera was a Sony A7R 36.4 megapixels camera, with a Sony FE $35 \mathrm{~mm} \mathrm{f} / 2.8$ ZA Carl Zeiss Sonnar $\mathrm{T}^{*}$ lens. The hyperspectral camera was the $2 \mathrm{D}$ frame camera prototype FPI2012b, which is based on an adjustable Fabry-Pérot interferometer (FPI) acquiring spectral bands using a time sequence based process, i.e., the acquisition is not simultaneous for all bands of the same hyperspectral cube (Honkavaara et al. 2017; Oliveira et al., 2016). The sensor was set to collect 36 bands from 510-890 nm with $15-30 \mathrm{~nm}$ of full width at half maximum (FWHM). The flight heights of the campaigns in Jokioinen were, $50 \mathrm{~m}$ giving a GSD of $5 \mathrm{~cm}$ for the hyperspectral data and $0.64 \mathrm{~cm}$ for the RGB data. The flight speed was $2 \mathrm{~m} / \mathrm{s}$ in all flights. Image overlaps were $84-87 \%$ in the forward direction and $65-81 \%$ between flight lines (see more details in Viljanen et al. 2018).

\subsection{Data processing chain}

The approach in the data processing was to generate ultra-dense point clouds using the RGB datasets and to calculate image mosaics and other spectral features using the HS data sets.

The datasets were processed using the processing chain developed at the Finnish Geospatial Research Institute (FGI) (Honkavaara et al., 2013, 2017, 2018; Näsi et al., 2018; Nevalainen et al., 2017). The steps are the following:

1. Applying laboratory calibration corrections to the images.

2. Determination of the geometric imaging model, including interior and exterior orientations of the images.

3. Using dense image matching to create a dense photogrammetric digital surface model (DSM).

4. Determination of a radiometric imaging model to transform the digital number (DNs) data to reflectance.

5. Calculating the radiometric output products.

6. Extracting spectral and 3D structural features.

7. Estimation of grass parameters.

The processing was divided to the geometric (steps: 2, 3) and radiometric (steps $1,4,5)$ processing steps.

Agisoft Photoscan Professional (version 1.3.5) was used for the photogrammetric processing, which involved image orientation estimation and DSM generation. The RGB images were processed separately and were used to calculate DSMs with 1 $\mathrm{cm}$ GSD for each date. The three reference bands of the FPI images were processed in a combined processing with the RGB images. The band registration for the rest of the bands of the FPI images was carried out using the approach developed by Honkavaara et al. (2017).

Radiometric processing of hyperspectral data sets was carried out using the FGI's radBA software (Honkavaara et al., 2013), which consider effects of changing illumination conditions, bidirectional reflectance distribution function (BRDF) phenomena and absolute reflectance transform.

\subsection{Estimation process and quality assessment}

Reflectance values from 35 spectral bands $(510-890 \mathrm{~nm})$ were extracted based on the average reflectance value of each grass reference plot taking into account the corresponding date of field and UAV measurements. The reflectance FPI orthomosaics were used to compute 11 spectral indices, also used as features (Chlorophyll index green (Cl-red-edge), Gitelson et al. (2003); Chlorophyll index red-edge (Cl-green), Gitelson et al. (2003); Green Normalised Difference Vegetation Index (GNDVI), Gitelson et al. (1996); MERIS terrestrial chlorophyll index (MTCI), Dash and Curran (2004); Modified Chlorophyll Absorption Ratio Index (MCARI), Daughtry et al. (2000); Modified Triangular Vegetation Index (MTVI), Haboudane. et al. (2004); Normalised Difference Vegetation Index (NDVI), Rouse et al. (1974); Optimisation of Soil Adjusted Vegetation Index (OSAVI), Rondeaux et al. (1996); Photochemical Reflectance Index (PRI(512.531)), HernándezClemente et al. (2011); Ratio Difference Vegetation Index (RDVI), Roujean and Breon (1995); Red edge inflection point 
(REIP), Guyot and Baret (1988);). Furthermore, 3D features based on CHMs were extracted for the plots; the features included average, median, minimum, maximum, standard deviation and percentiles $(70,80,90)$ of the canopy heights. The CHMs were generated using only RGB 3D photogrammetric derived data (see Viljanen et al. 2018). Spectral, vegetation indices and 3D features were further extracted for the whole test area in order to generate quality and quantity maps using the models estimated from the reference data plots.

Estimation and validation were done using the Random Forest (RF) (Breiman, 2001) and Multiple linear regression (MLR) implemented in the software Weka (Weka 3.8.1, University of Waikato). These machine learning algorithms were used to estimate grass sward yield quantity (above-ground biomass at 7 $\mathrm{cm}$ cutting height) and quality (D-value) parameter in two experiments, one using only $3 \mathrm{D}$ features and the second using hyperspectral reflectance bands and indices. To assess the prediction accuracy during the estimation of DMY and D-value for grass, we used Leave-one-out (LOO) method. The estimation accuracy was quantified using correlation coefficients (PCC) and root mean square error (RMSE) and RMSE\%.

\section{RESULTS}

In the DMY estimation, the use of only 3D features outperformed the spectral features in the middle of growing season (15th, 19th June) considering both RF and MLR (Table $1-2$, Figure 2). This situation was the opposite in the beginning of the growing season when the sward volume and density were low, as well as after the targeted silage harvesting date when the stand was already heading, and lodging occurred in the most heavily fertilized plots. In most of the cases, the use of RF algorithm lead slightly better estimation results than MLR.

When estimating D-value, there were only small differences between 3D and spectral features sets and between the estimators (RF and MLR). It is worth to note that DMY and Dvalue have strong correlation (Figure 1) in this material on primary growth, which can affect the results.

\begin{tabular}{|c|c|c|c|c|c|c|}
\hline & \multicolumn{2}{|c|}{ PCC } & \multicolumn{2}{|c|}{ RMSE \% } & \multicolumn{2}{|c|}{ RMSE } \\
\hline & DMY & $\begin{array}{c}\text { D- } \\
\text { value }\end{array}$ & DMY & $\begin{array}{c}\text { D- } \\
\text { value }\end{array}$ & $\begin{array}{c}\text { DMY } \\
\text { (kg DM/ha) }\end{array}$ & $\begin{array}{c}\text { D-value } \\
\text { (g /kg DM) }\end{array}$ \\
\hline \multicolumn{7}{|l|}{6 June } \\
\hline $3 \mathrm{D}$ & 0.79 & -0.55 & 19.41 & 1.96 & 215.98 & 14.81 \\
\hline Spectral & 0.94 & -0.02 & 11.02 & 1.75 & 122.65 & 13.16 \\
\hline \multicolumn{7}{|l|}{15 June } \\
\hline $3 \mathrm{D}$ & 0.96 & 0.83 & 8.9 & 0.95 & 201.05 & 7 \\
\hline Spectral & 0.92 & 0.85 & 12.48 & 0.87 & 281.77 & 6.36 \\
\hline \multicolumn{7}{|l|}{19 June } \\
\hline $3 \mathrm{D}$ & 0.97 & 0.56 & 9.02 & 2.22 & 262.22 & 15.39 \\
\hline Spectral & 0.96 & 0.51 & 11.26 & 2.21 & 327.24 & 15.34 \\
\hline \multicolumn{7}{|l|}{28 June } \\
\hline $3 \mathrm{D}$ & 0.93 & 0.78 & 13.03 & 1.7 & 564.51 & 11.22 \\
\hline Spectral & 0.95 & 0.75 & 12.25 & 1.79 & 530.94 & 11.84 \\
\hline
\end{tabular}

Table 1: Pearson correlation coefficient (PCC), the root mean square errors (RMSE) and the normalized RMSE (RMSE\%) of dry matter yield (DMY) and digestibility (D-value) using Random Forest (RF) algorithm.

\begin{tabular}{ccccccc}
\hline \multicolumn{1}{c}{ PCC } & \multicolumn{2}{c}{ RMSE\% } & \multicolumn{2}{c}{ RMSE } \\
\cline { 2 - 7 } & DMY & $\begin{array}{c}\text { D- } \\
\text { value }\end{array}$ & DMY & $\begin{array}{c}\text { D- } \\
\text { value }\end{array}$ & $\begin{array}{c}\text { DMY } \\
\text { (kg DM/ha) }\end{array}$ & $\begin{array}{c}\text { D-value } \\
\text { (g/kg DM) }\end{array}$ \\
\hline 6 June & & & & & & \\
3D & 0.74 & -0.46 & 21.53 & 1.75 & 239.67 & 13.17 \\
Spectral & 0.95 & 0.18 & 9.90 & 1.56 & 110.15 & 11.73 \\
\hline 15 June & & & & & & \\
3D & 0.95 & 0.86 & 10.43 & 0.86 & 235.42 & 6.34 \\
Spectral & 0.90 & 0.85 & 14.69 & 0.90 & 331.80 & 6.63 \\
\hline 19 June & & & & & & \\
3D & 0.97 & 0.65 & 10.19 & 1.92 & 296.08 & 13.33 \\
Spectral & 0.95 & 0.39 & 13.02 & 2.39 & 378.48 & 16.58 \\
\hline 28 June & & & & & & \\
3D & 0.81 & 0.77 & 21.17 & 1.76 & 917.54 & 11.58 \\
Spectral & 0.87 & 0.78 & 18.47 & 1.71 & 800.14 & 11.25 \\
\hline
\end{tabular}

Table 2: Pearson correlation coefficient (PCC), the root mean square errors (RMSE) and the normalized RMSE (RMSE\%) of dry matter yield (DMY) and digestibility (D-value) using Multi Linear Regression Models (MLR)
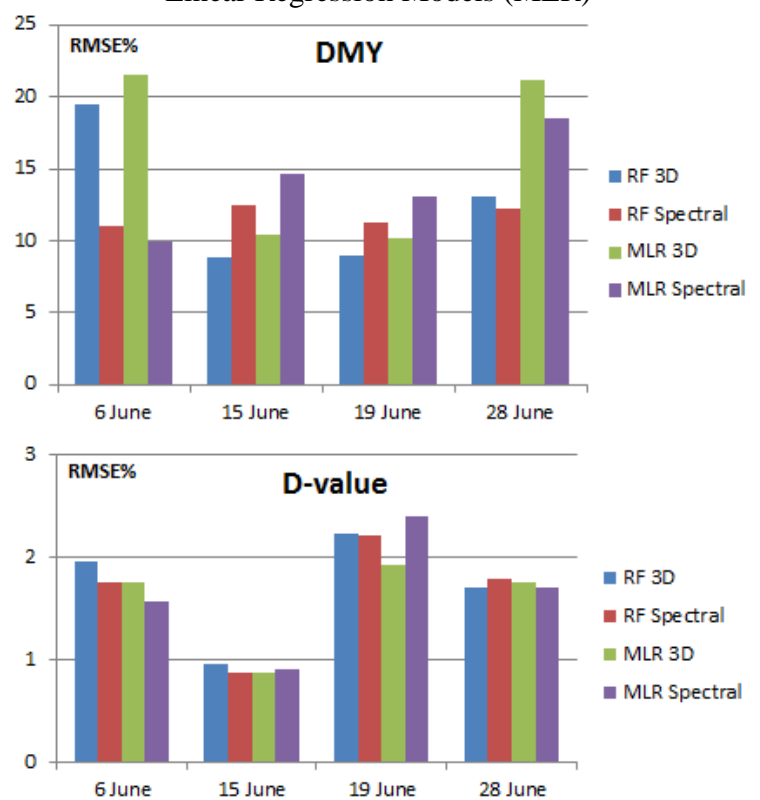

Figure 2: The normalized RMSE (RMSE\%) of dry matter yield (DMY) (up) and digestibility (D-value) (down)

Grass quantity (Figure 3) and quality (Figure 4) maps were calculated covering the entire test site. In the DMY maps, the red points are correspond to regions with low DMY values, while the green points correspond to areas with the higher values (Figure 3 ). In the quality map (figure 4 ), D-value is decreasing from high values (green) to low values (red) during measurement time.

In most of the cases, maps based on RF and MLR were similar with same date but in the first measurement day, MLR selected only a constant value to model D-value, not any 3D feature, which is clearly visible in Figure 4. Furthermore, in June 19, the use of spectral features in MLR lead significantly lower DMY values than RF for the same date. This indicates that RF models generated in this study were more stable than MLR models.

There were not notable differences between 3D and spectral features in the first two dates for quantity, but differences were visible, especially in the two latest datasets both in the biomass and quality maps. 

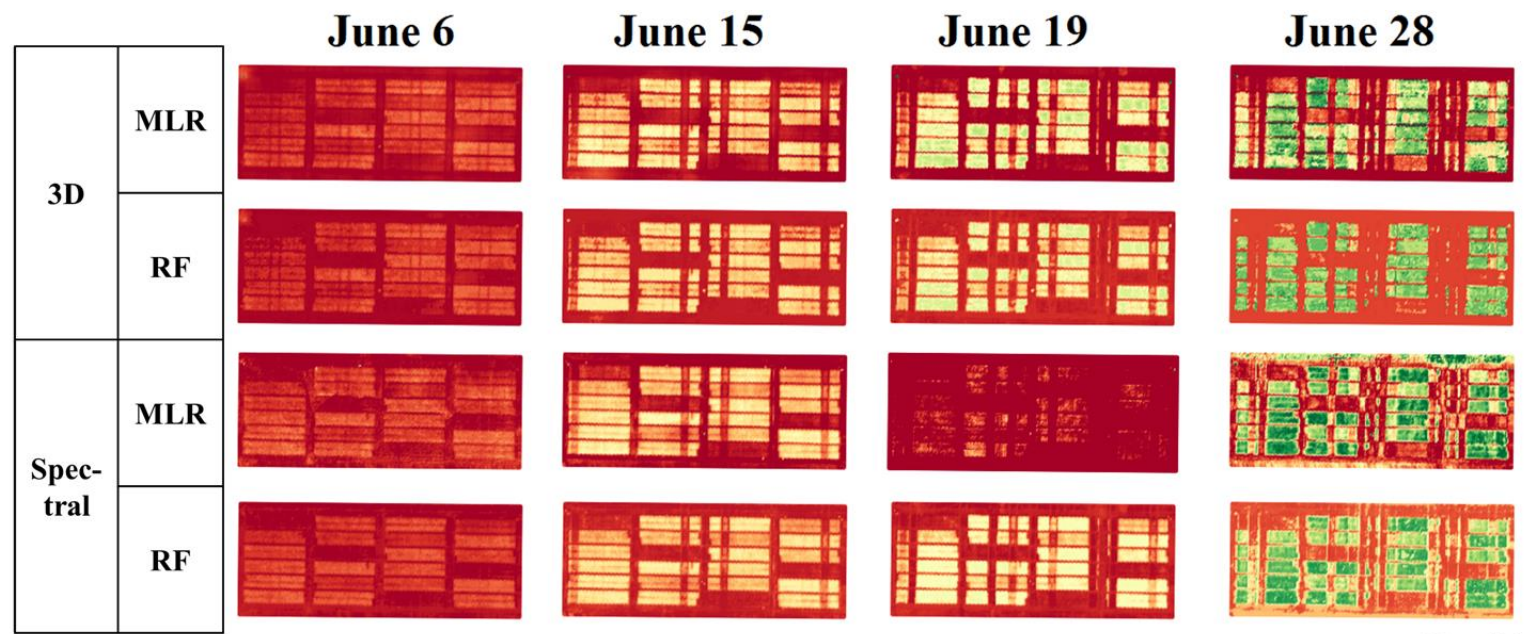

Dry biomass

(kg DM/ha)

1000

2000

3000

4000

5000

6000
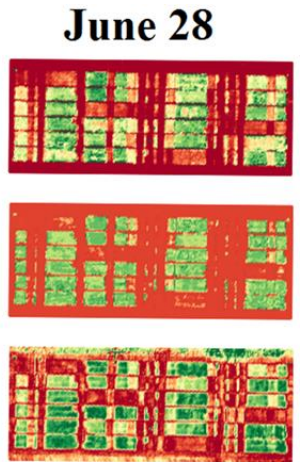

Figure 3: Dry biomass (DMY) maps of the test area for four measurements days using RF and MLR algorithms trained with 3D and spectral features.

June 6

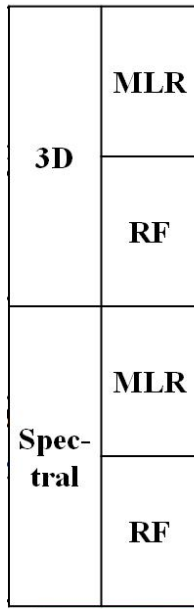

780
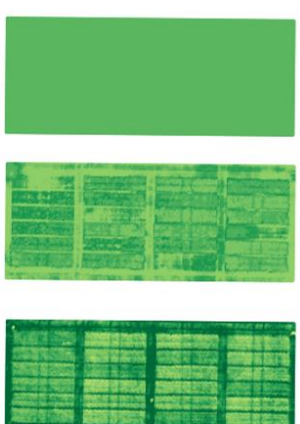

760

740

June 15
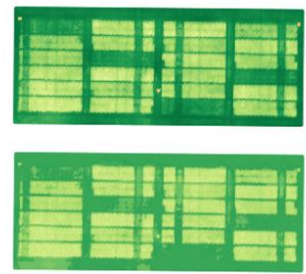

June 19

June 28
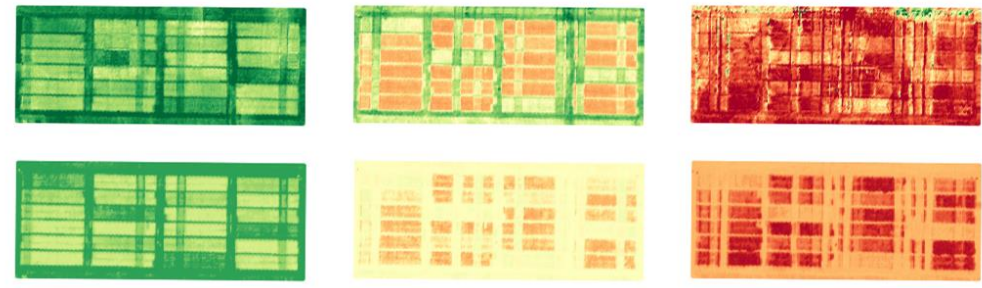

720

700

680

660

D-value

$3 \mathrm{D}$ and spectral features.

\section{CONCLUSIONS}

This study investigated and compared UAV machine learning techniques, based on spectral and 3D data, for managing and monitoring silage grass swards.

The most accurate results were obtained in the second measurement day (15th June) which was near to the optimal harvesting time and generally RF outperformed MLR slightly. When tested with the leave-one-out-estimation, the best root mean squared error (RMSE\%) were $8.9 \%$ for the DMY using $3 \mathrm{D}$ features. The best estimation of D-value using RF algorithm $($ RMSE\% $=0.87 \%)$ was obtained using spectral features.

Although, the spectral features have not outperformed the 3D features for all dates, overall, it has presented best or near results compared to $3 \mathrm{D}$ features, which indicates that spectral features have more stability for the quality parameter estimation throughout different dates.

Grass quality and quantity maps covering the entire test site showed clearly internal variability in the field and temporal changes during growing season. The results show that the lowcost drone remote sensing yielded promising precision both for biomass and quality parameter estimation, offering an excellent tool for efficient and accurate management of silage grass production.

\section{ACKNOWLEDGEMENTS}

The authors would like to acknowledge funding by Business Finland DroneKnowledge-project (Dnro 1617/31/2016) and by the ICT Agri ERA-NET 2015 GrassQ-project (Project id 35779). 


\section{REFERENCES}

Aasen, H., Burkart, A., Bolten, A., Bareth, G., 2015. Generating 3D hyperspectral information with lightweight UAV snapshot cameras for vegetation monitoring: From camera calibration to quality assurance. ISPRS Journal of Photogrammetry and Remote Sensing, 108(2015), pp. 245-259.

Aasen, H., Honkavaara, E., Lucieer, A., \& Zarco-Tejada, P. 2018. Quantitative remote sensing at ultra-high resolution with uav spectroscopy: A review of sensor technology, measurement procedures, and data correction workflows. Remote Sensing, 10(7), 1091

Aastveit, A.H., Marum, P., 1989. Accuracy of near infrared reflectance spectroscopy in the determination of IVDMD in forage. Norwegian Journal of Agricultural Sciences 3, 211-219.

Aastveit, A.H.; Marum, P. 1989. Accuracy of near infrared reflectance spectroscopy in the determination of IVDMD in forage. Norwegian Journal of Agriculturar Sciences 3: 211-219.

Bareth, G., \& Schellberg, J. (2018). Replacing Manual Rising Plate Meter Measurements with Low-cost UAV-Derived Sward Height Data in Grasslands for Spatial Monitoring. $P F G-$ Journal of Photogrammetry, Remote Sensing and Geoinformation Science, 86(3-4), 157-168.

Bendig, J., Yu, K., Aasen, H., Bolten, A., Bennertz, S., Broscheit, J., ... \& Bareth, G. (2015). Combining UAV-based plant height from crop surface models, visible, and near infrared vegetation indices for biomass monitoring in barley. International Journal of Applied Earth Observation and Geoinformation, 39, 79-87.

Breiman, L., 2001. Random forests. Machine learning, 45(1), pp. 5-32.

Clemente, R., Navarro-Cerrillo, R.M., Suárez, L., Morales, F., Zarco-Tejada, P.J., 2011. Assessing structural effects on PRI for stress detection in conifer forests. Remote Sens. Environ., 115, 2360-2375.

Dash, J., Curran, P.J., 2004. The MERIS terrestrial chlorophyll index. Int. J. Remote Sens. 25, 5403-5413.

Daughtry, C.S.T., Walthall, C.L., Kim, M.S., de Colstoun, E.B., McMurtrey, J.E., 2000. Estimating corn leaf chlorophyll concentration from leaf and canopy reflectance. Remote Sens. Environ. 74, 229-239.

Geipel, J., Link, J., Wirwahn, J.A., Claupein, W., 2016. A programmable aerial multispectral camera system for in-Season crop biomass and nitrogen content estimation. Agriculture 6,1, 4.

Gitelson, A.A., Kaufman, Y.J., Merzlyak, M.N., 1996. Use of a green channel in remote sensing of global vegetation from EOSMODIS. Remote Sens. Environ. 58, 289-298.

Gitelson, A.A., Gritz, Y., Merzlyak, M.N., 2003. Relationships between leaf chlorophyll content and spectral reflectance and algorithms for non-destructive chlorophyll assessment in higher plant leaves. J. Plant Physiol. 160, 271-282.

Guyot, G., Baret, F., 1988. Utilisation de la haute resolution spectrale pour suivre l'etat des couverts vegetaux. Spectr. Signat. Objects Remote Sens. 287, 279.
Haboudane, D., Miller, J.R., Pattey, E., Zarco-Tejada, P.J., Strachan, I.B., 2004. Hyperspectral vegetation indices and novel algorithms for predicting green LAI of crop canopies: Modeling and validation in the context of precision agriculture. Remote Sens. Environ. 90, 337-352.

Honkavaara, E., Saari, H., Kaivosoja, J., Pölönen, I., Hakala, T., Litkey, P., Mäkynen, J., Pesonen, L., 2013. Processing and Assessment of Spectrometric, Stereoscopic Imagery Collected Using a Lightweight UAV Spectral Camera for Precision Agriculture. Remote Sensing, 5(10), pp. 5006-5039.

Honkavaara, E., Rosnell, T., Oliveira, R., Tommaselli, A., 2017. Band registration of tuneable frame format hyperspectral UAV imagers in complex scenes. ISPRS Journal of Photogrammetry and Remote Sensing, 134(2017), pp. 96-109.

Honkavaara, E., Khoramshahi, E., 2018. Radiometric Correction of Close-Range Spectral Image Blocks Captured Using an Unmanned Aerial Vehicle with a Radiometric Block Adjustment. Remote Sensing, 10(2), 256, doi:10.3390/rs 10020256

Li, W., Niu, Z., Chen, H., Li, D., Wu, M., Zhao, W., 2016. Remote estimation of canopy height and aboveground biomass of maize using high-resolution stereo images from a low-cost unmanned aerial vehicle system. Ecological Indicators, 67(2016), pp. 637-648, doi.org/10.1016/j.ecolind.2016.03.036.

Nevalainen, O., Honkavaara, E., Tuominen, S., Viljanen, N., Hakala, T., Yu, X., Hyyppä, J., Saari, H., Pölönen, I., Imai, N.N., Tommaselli, A.M.G., 2017. Individual Tree Detection and Classification with UAV-Based Photogrammetric Point Clouds and Hyperspectral Imaging. Remote Sensing, 9(3), 185, doi.org/10.3390/rs9030185.

Näsi, R., Viljanen, N., Kaivosoja, J., Alhonoja, K., Hakala, T., Markelin, L., Honkavaara, E. 2018a. Estimating Biomass and Nitrogen Amount of Barley and Grass Using UAV and Aircraft Based Spectral and Photogrammetric 3D Features. Remote Sensing, 10(7), 1082

Näsi, R., Viljanen, N., Oliveira, R., Kaivosoja, J., Niemeläinen, O., Hakala, T., Markelin, L., Nezami, S., Suomalainen, J., Honkavaara, E. 2018b. Optimizing Radiometric Processing and Feature Extraction of Drone Based Hyperspectral Frame Format Imagery for Estimation of Yield Quantity and Quality of a Grass Sward. Int. Arch. Photogramm. Remote Sens. Spatial Inf. Sci., XLII-3, pp 1305-1310. doi: 10.5194/isprs-archives-XLII-3$1305-2018$

Oliveira, R.A., Tommaselli, A.M. and Honkavaara, E., 2016. Geometric calibration of a hyperspectral frame camera. The Photogrammetric Record, 31(155), pp. 325-347, doi.org/10.1111/phor.12153.

Oliveira, R. A., Tommaselli, A. M., Honkavaara, E., 2019. Generating a hyperspectral digital surface model using a hyperspectral 2D frame camera. ISPRS Journal of Photogrammetry and Remote Sensing, 147, 345-360. https://doi.org/10.1016/j.isprsiprs.2018.11.025.

Rondeaux, G., Steven, M., Baret, F., 1996. Optimization of soiladjusted vegetation indices. Remote Sens. Environ. 55, 95-107. 
Rouse, J.W. Monitoring vegetation systems in the Great plains with ERTS; NASA: Washington, DC, USA, 1974

Roujean, J.-L.; Breon, F.-M. Estimating PAR absorbed by vegetation from bidirectional reflectance measurements. Remote Sens. Environ. 1995, 51, 375-384, doi:10.1016/00344257(94)00114-3.

Rueda-Ayala, V. P., Peña, J. M., Höglind, M., BengocheaGuevara, J. M., \& Andújar, D. (2019). Comparing UAV-Based Technologies and RGB-D Reconstruction Methods for Plant Height and Biomass Monitoring on Grass Ley. Sensors, 19(3), 535 .

Viljanen, N., Honkavaara, E., Näsi, R., Hakala, T., Niemeläinen, O., \& Kaivosoja, J. 2018. A novel machine learning method for estimating biomass of grass swards using a photogrammetric canopy height model, images and vegetation indices captured by a drone. Agriculture, 8(5), 70. 